\title{
Campylobacter Fetus Subspecies Fetus Meningitis with Chronic Alcoholism and Diabetes Mellitus
}

\author{
Hiroyuki KaTO, Hideyuki WaKASUGI, Toshio MUKUTA, \\ Masayuki FURUKAWA, Masaki YoKOTA, Yukio YAMADA, \\ Akihiro FUNAKOSHI and Muneaki ABE
}

\begin{abstract}
A case of Campylobacter fetus subspecies fetus meningitis is reported. The patient had underlying diseases, namely chronic alcoholism and diabetes mellitus. The infection did not respond to Piperacillin and Cefotaxime, but did respond to Ampicillin and Moxalactam. The patient was discharged on the 33rd hospital day showing no neurological deficit complications, and has remained free of recurrent disease for one month after the discontinuation of therapy.
\end{abstract}

Key words: Ampicillin, Moxalactam, Cerebrospinal fluid, Underlying illness

Campylobacter fetus subspecies fetus (C. fetus herein), previously classified as Vibrio fetus, had been considered a pathogen in only cattle and sheep until Vinzent et al (1) first published a description of human disease caused by it. Human isolates of Campylobacter have recently been identified three separate species and subspecies (Campylobacter fetus subspecies fetus, Campylobacter jejuni and Campylobacter coli) (2). C. fetus is, however, an infrequent cause of human infection. This subspecies has been associated with septicemia, thrombophlebitis, meningitis, endocarditis, peumonia and arthritis, mostly in elderly or immunocompromised patients $(3,4)$. At least 39 cases of central nervous system infection with $\mathrm{C}$. fetus in adults have been recorded since 1962, when the first such case was reported (3-9). We herein report a recent case of meningitis due to $C$. fetus that illustrates some characteristic features of this infection.

\section{CASE REPORT}

A 55-year-old man was admitted to the National Kyushu Cancer Center on Dec. 13, 1988, com- plaining of a 7-day fever, chilly sensation, headache, nausea, vomiting, myalgia of bilateral lower extremities, weakness of limbs and gait disturbance. He had a 35-year history of heavy alcohol intake and had been seen at our outpatient department for alcohol-induced liver dysfunction and diabetes mellitus (DM). The latter had been relatively well controlled with 18 daily units of intermediate type insulin. The patient had been hospitalized in another hospital for 7 months due to lung tuberculosis 8 months prior to the current admission. He showed no diarrhea and denied any animal contact.

At the time of admission, his body temperature was $39.0^{\circ} \mathrm{C}$, blood pressure $129 / 70 \mathrm{mmHg}$ and pulse rate 102 beat/min. Neurological examination showed slight neck stiffness, mild mental confusion, muscle weakness of limbs and diminished deep tendon reflexes. Marked grasp pain of the bilateral sural muscles was noted. There was no regional lymphadenopathy, no skin lesions, and no insect bites. Other general physical examinations showed nothing in particular.

Initial laboratory findings are shown in Table 1.

From Department of Internal Medicine, National Kyushu Cancer Center, Fukuoka

Received for publication August 2, 1989; Accepted for publication July 24, 1990

Reprint requests should be addressed to Hiroyuki Kato, MD, Department of Internal Medicine,

Saga Medical School, 5-1-1 Nabeshima, Nabeshima-cho, Saga 849, Japan 
Table 1. Laboratory data on admission.

\begin{tabular}{|c|c|c|}
\hline $\begin{array}{l}\text { CBC } \\
\text { WBC } 21800 / \mu \mathrm{l} \\
\text { (Myelo } 1, \mathrm{St} 12, \\
\text { Seg 67, Ly 14, Mo 6\%) } \\
\text { RBC } 275 \times 10^{4} / \mu \mathrm{l} \\
\text { Hb } 9.6 \mathrm{~g} / \mathrm{dl} \\
\text { Ht } 29.8 \% \\
\text { Platelet } 16.9 \times 10^{4} / \mu \mathrm{l}\end{array}$ & 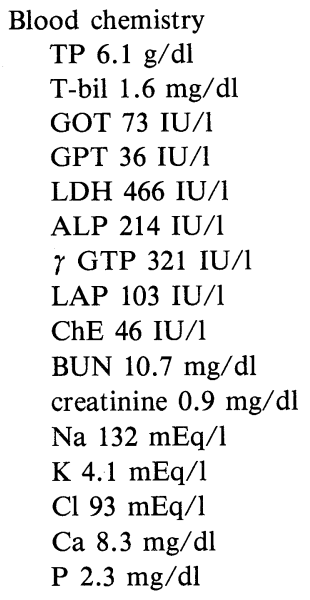 & $\begin{array}{l}\text { Serological findings } \\
\text { CRP } 5.82 \mathrm{mg} / \mathrm{dl} \\
\text { RA test }(-) \\
\text { LE test }(-) \\
\text { Widal test }(-) \\
\text { Well-Felix test }(-)\end{array}$ \\
\hline
\end{tabular}

Urinalysis results were normal except for urinary glucose. Marked leukocytosis with a left shift and mild anemia were noted. Blood chemistry showed liver dysfunction, in particular $\gamma$ GTP was elevated. The erythrocyte sedimentation rate (ESR) was rapid and $\mathrm{C}$-reactive protein (CRP) was obviously positive. $\mathrm{X}$ rays of the chest showed a small, calcified nodular lesion in the left upper lung field. The electrocardiogram was within normal limits.

The cerebrospinal fluid (CSF) findings are summarized in Table 2. The initial CSF sample showed leukocytosis, and CSF culture after two days contained gram negative bacilli, later identified as $\mathrm{C}$. fetus. The blood glucose level, measured at the time of the initial spinal tap, was $220 \mathrm{mg} / \mathrm{dl}$. The culture

Table 2. CSF findings.

\begin{tabular}{|c|c|c|c|c|}
\hline & Dec. 15 & Dec. 21 & Dec. 27 & Jan. 6 \\
\hline glucose (mg/dl) & 106 & 101 & 83 & 104 \\
\hline protein $(\mathrm{mg} / \mathrm{dl})$ & 85 & 150 & 60 & 40 \\
\hline chloride $(\mathrm{mEq} / \mathrm{l})$ & 115 & 117 & 122 & 121 \\
\hline cell count $\left(/ \mathrm{mm}^{3}\right)$ & 400 & 108 & 15 & 12 \\
\hline \multicolumn{5}{|l|}{ cell analysis } \\
\hline lymphocyte & $74.5 \%$ & & $97.0 \%$ & $100.0 \%$ \\
\hline neutrophil & $22.5 \%$ & & & \\
\hline monocyte & $3.0 \%$ & & $3.0 \%$ & \\
\hline bacterial culture & $(+)^{*}$ & $(-)$ & $(-)$ & $(-)$ \\
\hline
\end{tabular}

*gram-negative bacilli identified as C.fetus. of acid-fast bacteria of CSF was negative. The blood culture was performed twice in the first four hospital days and the results were also negative. Furthermore, the brain CT scan done on the 5th hospital day was also within normal limits. Antibiotic therapy of Piperacillin (PIPC) $2.0 \mathrm{~g}$ and Cefotaxime (CTX) $1.0 \mathrm{~g}$ administered intravenously every 8 $\mathrm{h}$ was begun immediately after admission. Despite the above-mentioned therapy, the patient's body temperature continued to rise, reaching $39.8^{\circ} \mathrm{C}$. Therefore the PIPC and CTX antibiotic therapy was discontinued, and Ampicillin (ABPC) $2.0 \mathrm{~g}$ and Moxalactam (LMOX) $1.0 \mathrm{~g}$, were intravenously administered every $6 \mathrm{~h}$. The patient was afebrile, and within the next few days all signs and symptoms were resolved. Antibiotic therapy was discontinued on the 28th hospital day. Because of the hyperglycemia (blood glucose $368 \mathrm{mg} / \mathrm{dl}$ ) measured on admission, the blood glucose level was controlled by $18 \mathrm{U} /$ day of intermediate-type insulin and 8-16 $\mathrm{U} /$ day of regular insulin for 11 days. This was followed by 18-30 U/day of intermediate-type insulin alone. As the meningitis improved, the DM control became better, and on the 14th hospital day the fasting blood glucose was $126 \mathrm{mg} / \mathrm{dl}$ and the hemoglobin $\mathrm{A} 1 \mathrm{C}$ ( $\mathrm{HbA}_{1 \mathrm{C}}$ ) was $4.7 \%$.

On the 33rd hospital day, he was discharged with no complication involving neurological deficit. At one month after discontinuation of therapy, the patient has no recurrence of the disease. 
The organism isolated from the initial CSF culture was sensitive to Ampicillin (3+), Cefotaxime $(+)$, Cefmetazol $(+)$, Moxalactam $(+)$, Gentamycin $(3+)$, Erythromycin $(2+)$ but resistant to Piperacillin and Cephazolin.

\section{DISCUSSION}

C. fetus infection occurs predominantly in patients with an underlying illness, particularly chronic alcoholism (4) or DM, as illustrated by our case. Most patients recover fully with iv antibiotic therapy $(3,10)$, although it seems that the prognosis primarily depends upon the severity of the underlying disease (4). Despite the long history of chronic alcoholism of our patient, he had no mental disorders or liver cirrhosis. The DM was not too advanced and triopathies were not seen. It was thought he could be discharged without any complications as the underlying illnesses were not too severe.

C. fetus has a peculiar tendency to involve the vascular endothelium in human infection, bringing about endocarditis and thrombophlebitis (11). When involved neurologically, this infection leads to cerebral vascular disorders (CVD) such as subarachnoidal hemorrhage or cerebral infarction due to small cerebral arterial occulusions with fibrin clots. The CVD is more common than meningitis (12). Our patient did not show obvious signs suggesting CVD. The brain CT was also normal. When C. fetus infection is suspected, treatment with antibiotics should be started as soon as possible to prevent cerebral vascular complications which are likely fetal.

To date there are no reports on the type of antibiotics to use and the recommended duration of treatment. Erythromycin has been frequently used $(10,13)$, with rapid response. However, some cases of non-response have also been reported (4). In vitro, C. fetus is susceptible to a wide range of antibiotics, the most active being aminoglycoside and ampicillin (14). In the present patient, $C$. fetus was resistant to PIPC and sensitive to CTX (+), LMOX $(+)$ and more sensitive to ABPC $(3+)$. Therefore, the clinical response to antibiotic therapy in our case was perhaps mainly due to ABPC, and secondarily to LMOX and CTX as reported in the literature (14). The potency of the latter two drugs also cannot be disregarded.

\section{REFERENCES}

1) Vinzent R, Dumas J, Picard N. Septicémie grave au cours de la grossesse due à un vibrion: Avortement consécutif. Bull Acad Natl Med 131: 90, 1947.

2) Blaser MJ, Reller LB. Campylobacter enteritis. N Engl J Med 305: 1444, 1981.

3) Schmidt U, Chmel H, Kaminski Z, Sen P. The clinical spectrum of Campylobacter fetus infections: Report of five cases and review of the literature. Q J Med 49: 431, 1980.

4) Francioli P, Herzstein J, Grob JP, Vallotton JJ, Mombelli G, Glauser MP. Campylobacter fetus subspecies fetus bacteremia. Arch Intern Med 145: 289, 1985.

5) Gubina M, Zajc-Satler J, Mehle J, et al. Septicaemia and meningitis with Campylobacter fetus subspecies intestinalis. Infection 4: 115, 1976.

6) Hanai N, Odawara H, Masuda G, Yano Y, Saku K. Campylobacter fetus meningitis in an adult male. Kansenshogaku Zasshi 58: 441, 1984 (in Japanese).

7) Yamazaki E, Kitano A, Mizuoka K. Four cases of infection by Campylobacter fetus ssp. fetus. Rinsho Byori 34: 716, 1986 (in Japanese).

8) Iida $Y$, Sunaga K, Maehara K, et al. Two cases of Campylobacter fetus meningitis. Kansenshogaku Zasshi 60: 271, 1986 (in Japanese).

9) Rao KV, Ralston RA. Meningitis due to Campylobacter fetus intestinalis in a kidney transplant recipient. A case report. Am J Nephrol 7: 402, 1987.

10) Guerrant RL, Lahita RG, Winn WC, Roberts RB. Campylobacteriosis in man: Pathogenic mechanism and review of 91 bloodstream infections. Am J Med 65: 584, 1978.

11) Vasely D, Macintyre DS, Ratzan KR. Bilateral deep brachial vein thrombophlebitis due to Vibrio fetus. Arch Intern Med 135: 994, 1975.

12) Gunderson $\mathrm{CH}$, Sack GE. Neurology of Vibrio fetus infection. Neurology 21: 307, 1971.

13) Butzler JP, Dekeyser P, Lafontatine T. Susceptibility of related Vibrios and Vibrio fetus to twelve antibiotics. Antimicrob Agents Chemother 5: 86, 1974.

14) Spelhaug DR, Gilchrist MJR, Washington JA II. Bacteriocidal activity of antibiotics against Campylobacter fetus subspecies intestinalis. J Infect Dis 143: 500, 1981. 